IZA DP No. 8473

Returns to University Quality in Australia:

A Two-Stage Analysis

David Carroll

Chris Heaton

Massimiliano Tani

September 2014 


\title{
Returns to University Quality in Australia: A Two-Stage Analysis
}

\author{
David Carroll \\ UNSW Canberra \\ Chris Heaton \\ Macquarie University \\ Massimiliano Tani \\ UNSW Canberra \\ and IZA

\section{Discussion Paper No. 8473 \\ September 2014} \\ IZA
P.O. Box 7240
53072 Bonn
Germany \\ Phone: +49-228-3894-0 \\ Fax: +49-228-3894-180 \\ E-mail: iza@iza.org
}

\begin{abstract}
Any opinions expressed here are those of the author(s) and not those of IZA. Research published in this series may include views on policy, but the institute itself takes no institutional policy positions. The IZA research network is committed to the IZA Guiding Principles of Research Integrity.
\end{abstract}

The Institute for the Study of Labor (IZA) in Bonn is a local and virtual international research center and a place of communication between science, politics and business. IZA is an independent nonprofit organization supported by Deutsche Post Foundation. The center is associated with the University of Bonn and offers a stimulating research environment through its international network, workshops and conferences, data service, project support, research visits and doctoral program. IZA engages in (i) original and internationally competitive research in all fields of labor economics, (ii) development of policy concepts, and (iii) dissemination of research results and concepts to the interested public.

IZA Discussion Papers often represent preliminary work and are circulated to encourage discussion. Citation of such a paper should account for its provisional character. A revised version may be available directly from the author. 
IZA Discussion Paper No. 8473

September 2014

\section{ABSTRACT}

\section{Returns to University Quality in Australia: A Two-Stage Analysis}

This study investigates the relationship between university quality and graduate starting salaries using pooled Australian data from the Graduate Destination survey and a two-stage estimation methodology. The results suggest that average starting salaries for young undergraduates differ significantly across universities after controlling for relevant confounding factors, though the range of university effects is fairly small in relation to other salary determinants, particularly course area. The results are robust to alternative specifications and suggest that employers generally do not place salary premia on attending a high-quality or prestigious university, at least upon workforce entry.

JEL Classification: A22, I23, J24

Keywords: human capital, returns to education, university choice

Corresponding author:

Massimiliano Tani

School of Business

UNSW Canberra

PO Box 7916

Canberra BC 2610

Australia

E-mail:m.tani@adfa.edu.au 


\section{Introduction}

Over the past two decades, universities in a number of English-speaking countries like Australia, Ireland, the United Kingdom and New Zealand have faced increased government pressure on raising their teaching and research quality standards. This pressure has taken the form of financial incentives for achieving desired educational targets, to which universities have responded by recruiting established or promising researchers, and implementing activities to manage and enhance teaching performance, such as extra training for academics and well defined course criteria against which students can form and evaluate their expectations.

Despite these initiatives, little research exists about the nexus between the 'quality' of the tertiary institution one graduates from and the earnings, or job quality, obtained in the labour market upon graduation. Theories of human capital formation purport the existence of a positive relationship between institutional quality and labour market outcomes as a result of superior human capital accumulation, signalling of ability, or their combined effect (e.g. Rumberger \& Thomas, 1993; Brewer, Eide \& Ehrenberg, 1999; Monks, 2000; Dale \& Krueger, 2002; Long, 2008). If empirically supported, this hypothesis justifies the existence of differential undergraduate fees across universities, as progressively introduced in the United Kingdom and Australia.

One major obstacle to empirical analysis in this topic is the common lack of data matching several individuals with the characteristics of the educational institution attended. Typically the dependent variable is binary (e.g. high/low quality) to overcome the small number of cases in each institution. The limited literature generally finds very small or no positive earning premia associated with better quality or more prestigious universities, implying that earning differentials are effectively determined by course area and individual performance (e.g. McGuinness, 2003; Betts, Ferrall \& Finnie, 2007; Birch, Li \& Miller, 2009).

This paper overcomes the small-data limitation as well as the selectivity affecting university choice thanks to a large pooled data sample sourced from the Graduate Destination Survey (GDS). This survey collects information on graduates across all Australian universities. Using a two-stage estimation methodology, the empirical analysis tests whether the starting salaries of young Australian bachelor degree graduates differ on the basis of the university attended, coeteris paribus, and whether 
any differences in their returns to education are associated with institutional characteristics commonly associated with quality, such as the staff to student ratio and the proportion of faculty holding a $\mathrm{PhD}$.

This study contributes to the literature on two fronts. First, it applies a novel approach for dealing with the potential non-random selection of students of different ability levels into universities exploiting the cut-off scores of the Australian Tertiary Admissions Rank (ATAR), which determines their admission. Second, in addition to estimating the returns to attending specific universities, it attempts to explain these differences in returns empirically on the basis of widely accepted measures of university quality.

The results show that estimated returns do vary significantly across universities, but the range of the effects is 12 percentage points (p.p.) after controlling for exogenous personal and enrolment characteristics, compared with 61 p.p. across course areas. There are only few significant differences at the top and bottom of the distribution of 35 tertiary institutions relative to the middle, and these do not appear to be particularly strong. A one standard deviation increase in university quality is associated with an increase of 0.19 p.p. in the estimated university-specific wage premium.

These results suggest that the provision of human capital accumulation is relatively consistent across Australia's public universities, as found in other countries, and suggests that universities have little justification in raising their tuition fees relative to others solely on the basis of quality differences.

The rest of this paper is organised as follows. Section 2 presents a brief literature review and outlines our contribution. Section 3 describes the data and variables used in our analysis. Section 4 describes our two-stage estimation methodology. Results are presented and discussed in Section 5. Conclusions and implications are presented in Section 6.

\section{Literature}

In the vast literature estimating the returns to attending a high-quality college or university, “quality” has been measured in numerous ways. These include selectivity in admissions (e.g. Brewer et al, 1999; Monks, 2000; Thomas \& Zhang, 2005), institution type (e.g. Monks, 2000; Birch et al., 2009), reputation (e.g. Milla, 2012), and various institution-level inputs, such as staff to student ratios, mean faculty salaries, and expenditures per student (e.g. Black \& Smith, 2006; Betts et al., 2007; 
Long, 2008). Black and Smith (2006) use factor analysis to combine correlated institution-level inputs into a single, and intuitively more reliable, measure of latent college quality. In spite of these differences in measurement, most studies find that graduating from a high-quality institution is associated with increased post-completion earnings, but the magnitude of the estimated effect ranges from negligible to large (for a survey see Brand and Halaby, 2003).

From a theoretical perspective, there are two main reasons why institutional quality may influence graduates’ earnings. Under a human capital interpretation (Becker, 1964), institutions may facilitate the production of human capital at different rates. If institutional factors such as class sizes and faculty qualifications are important in the human capital production function, then graduates of "better" institutions (those with most favourable ratios) should be paid a premium due to their enhanced productivity relative to their peers.

Under a signalling interpretation (Spence, 1973), employers, believing that attending a prestigious university is correlated with productivity, will pay a premium to graduates from these institutions, especially when institutional quality is more visible to employers than individual productivity, such as in the case of recent graduates with limited work histories. These two explanations are not necessarily mutually exclusive. In either case, as noted by Monks (2000), individuals seeking to maximise the net present value of their lifetime wealth should attempt to enrol in an institution whose graduates earn higher wages.

Establishing a causal relationship between institutional quality and earnings is difficult and problematic due to selection on the part of both the student and the institution (Long, 2008). As a result, students admitted to high-quality institutions may possess different characteristics to those admitted to lower-quality ones. If these characteristics are positively correlated with earnings, the premium associated with attending a high-quality institution will be overstated. To address this selection problem, most studies rely on what Heckman and Robb (1985, p. 243) refer to as "selection on observables”, whereby variables typically associated with selection bias, such as test scores and family socioeconomic background, are entered as covariates in an earnings model (e.g. Rumberger \& Thomas, 1993; Holmlund, 2009; Monks, 2000; Chevalier \& Conlon, 2003; Thomas \& Zhang, 2005; Birch et al., 2009). Monks (2000), for example, uses Armed Forces Qualifications Test scores as a 
measure of academic ability and preparation. He found that graduates from highly or most selective institutions tend to earn more than those from less selective ones, and that graduates from researchintensive and private universities earn more than those from liberal arts colleges and public institutions.

Dale and Krueger (2002) account for selection by comparing the outcomes of selective elite college graduates against those who gained admission to a less-selective elite college. They generally found no difference in earnings between the two groups; however students from a low-income background did earn more if they attended a selective college. Their approach was criticised by Long (2008), who noted that there may be unobserved traits that prompt high-achieving students to attend less-selective colleges, which may in turn be correlated with their outcomes. As such, this technique may in fact exacerbate the selection problem.

Betts et al. (2007) employ a university fixed-effects approach, in which a set of university intercepts are included in the earnings model along with one or more university quality measures. To the extent that the most able students always attend certain universities, the intercepts remove the average ability of the university's student body from the earnings equation. They find that earnings are positively associated with high professor-student ratios and tuition fees, but only for males. Higher enrolments were associated with reduced earnings for graduates of both sexes. The key drawback of this approach is that it relies on variation in university characteristics over time, which may often be too strong an assumption in practice ${ }^{1}$. The inclusion of university intercepts nevertheless allows the returns to attending specific institutions to be estimated. Predicted earnings varied $26 \%$ across the 43 institutions in their study, but they cautioned that some of this may reflect sampling variation.

Brewer et al. (1999) use a multinomial logit to estimate the institution type chosen and then construct a correction factor based on Lee (1983), which is then included in the earnings equation as a covariate. Grouping colleges on the basis of selectivity, they report a large premium associated with attending an elite private college and a smaller premium to attending a middle-rated private collage, relative to a low-rated private college. A similar story is observed in relation to top-rated public institutions, though this evidence is weak due to small sample size. A limitation of the selection model

\footnotetext{
${ }^{1}$ Kingston and Smart (1990), for example, note that institutional rankings change little over time.
} 
approach is that it becomes difficult to implement as the number of institution types in the multinomial logit increases. The authors find little evidence of a selection effect, but emphasise that correcting for selectivity in the college selection process remains important in principle.

Long (2008) uses an instrumental variable approach to account for selection using college proximity as an instrument. He finds no significant effect of institutional quality on earnings using instrumental variables, but significant effects on a number of college characteristics when using ordinary least squares. As noted by Monks (2000), instrumental variables works well when there are few variables to instrument, but it becomes problematic as the number of variables increases. It also assumes the availability of suitable instruments, which must have a significant effect on institutional quality, while having no effect on earnings except via the instrumental variable. Finding instruments that meet these criteria may be difficult in practice.

While many studies investigate the returns to institutional quality in the USA and Europe, the Australian literature is much thinner. One notable study is that of Birch et al. (2009), who investigate whether the institution attended has an influence on graduates' starting salaries. Using data from the 2003 GDS and a selection on observables approach, they find little variation across university groups, echoing earlier results by Miller and Volker (1983), though variation in starting salaries between the universities with the lowest and highest estimated premia was 25 percentage points.

Relative to by Birch et al. (2009), this study controls for the potential self-selection of students of various abilities into universities of different quality. In addition, it controls for regional effects in their earnings model. This is likely to be relevant given the extent of regional wage differences in Australia (e.g. Mishra \& Ray, 2013), and the fact that most graduates find work in the region where their university is located, implying that the "true" effect of attending a particular institution may be overstated if it is located in a high-wage region. Finally, this study attempts to explain the differences in returns across universities by relating them directly to measures of quality covering both teaching and research.

\section{Data and variables}

The data used are pooled from three rounds of the Graduate Destination Survey (2010-2012). The GDS is a national survey of Australian higher education graduates, administered by Graduate 
Careers Australia (GCA) since 1972. Each round consists of two separate collections to account for most Australian universities having two major graduation rounds each year. The GDS is conducted approximately four months after course completion. All new graduates from participating higher education institutions are invited to respond to the GDS, which includes all 40 Australian universities and a number of non-university higher education providers. Respondents are asked a range of questions relating to their activities on a given reference date with an emphasis on their labour market outcomes. The average response rate across the three rounds in the pooled sample was $61.5 \%$. Previous studies (e.g. Guthrie \& Johnson, 1997) have found that the GDS is not affected by nonresponse bias. We pool multiple years of data to increase the precision of the estimates, relying on the stability of the graduate labour market over the period (GCA, 2013).

Respondents are asked to report their annual salary in their main paid job. Since this earnings measure is less suitable for casual workers, the analysis is restricted to graduates in full-time jobs. The mean full-time starting salary of the graduates in the sample is \$48,698 in 2012 Australian dollars. To eliminate regional effects from the analysis, the annual salary variable is normalised by dividing it by the mean salary in the employment region and multiplying by 100 . The resulting variable has mean 100 and standard deviation 27.6, and is measured in percentage points. Normalisation is required because it is not possible to control for regional effects using the typical approach of regional dummy variables. This is due to the vast majority of new graduates finding work in the region where their university is located ( $92 \%$ of the graduates in the sample), leading to severe multicollinearity between regional and university dummies and inconsistent and unstable parameter estimates on the variables of interest.

The analysis is also restricted to "traditional" bachelor degree graduates aged less than 25 years at the time of the survey to reduce the influence of heterogeneity in work experience. The analysis is further restricted to Australian domestic students due to the under-representation of overseas graduates in the sample. Finally, salaries in the top and bottom $2 \%$ of the distribution are also excluded to minimise the influence of extreme outliers. This results in a sample of 36,204 graduates. Definitions and means of the variables used are presented in Table 1.

[Table 1 around here] 
The empirical analysis is restricted to the 37 Australian public universities, data on which can be found in the Commonwealth Higher Education Statistics Collection (HESC). Private universities and higher education providers are not subject to the same reporting requirements as public universities, making it impossible to find key data. This restriction is not a major concern because the vast majority of Australian higher education students enrol in a public university. ${ }^{2}$ Importantly, the University of Melbourne is excluded from the analysis, as it is impossible to reliably match its ATAR cut-off scores to GDS records.

Because the Code of Practice governing the use of data from the GDS discourages the publication of institutional results, we assign each university a random identifier based on broad university group. Four groups currently exist: the Group of Eight (Go8) consists of the universities generally considered to be the most prestigious and research intensive in Australia; ${ }^{3}$ the Australian Technology Network (ATN) consists of five universities, all former institutes of technology, with a heritage of working closely with industry; Innovative Research Universities Australia (IRUA) consists of seven universities, all formed in the 1960s and 1970s as research intensive universities; and the Regional Universities Network (RUN) comprises six universities located outside of capital cities. The groups were formed to promote the mutual objectives of the member institutions, and therefore represent universities with a similar style and focus. In addition, there are 11 universities that do not belong to a university group. To facilitate the analysis, we create 35 university dummy variables, with a Go8 university as the omitted reference category.

Summary statistics on the universities are presented in Table 2. These include the number of graduates, the ratio of full-time equivalent (FTE) academic staff to one hundred FTE students, and the percentage of academic staff with a $\mathrm{PhD} .{ }^{4}$ It is notable that Go8 universities tend to lead in terms of staff to student ratios and academic staff qualifications, both of which are typical indicators of institutional quality. Also notable is the relative heterogeneity of the university groups in relation to these characteristics.

\footnotetext{
${ }^{2}$ Public universities account for 93\% of all higher education student load in Australia (Department of Industry, Innovation, Climate Change, Science, Research and Tertiary Education [DIICCSRTE], 2013a).

${ }^{3}$ The University of Melbourne, not included in our study, is a member of the Go8.

${ }^{4}$ Staff to student ratios were constructed using data from DIICCSRTE (2013a, 2013b). Data on academic staff qualifications were drawn from DIICCSRTE (2013b).
} 
Since these indicators are noisy measures of latent university quality, we opt for composite indicator following Black and Smith (2006). Hence we apply a principal component analysis to the two university quality measures $(n=35)$, and the first principal component, explaining $71 \%$ of the total variance, was extracted as university quality indicator. ${ }^{5}$

[Table 2 around here]

Control variable for graduates’ academic ability is course-level data on ATAR cut-off scores sourced from the HESC (see Section 4). The ATAR is the main criterion for entry into most undergraduate degrees in Australia. ${ }^{6}$ It is a percentile score denoting a student's ranking relative to his or her peers upon completion of secondary education. The ATAR cut-off scores denote the lowest ATAR that was accepted into a particular course of study. The cut-off scores were matched to the graduates in the sample on the basis of their institution and course area.

\section{Estimation methodology}

One of the key challenges in estimating the returns to university quality is addressing the potential non-random selection of students into universities. This is exacerbated by the fact that the data do not contain individual-level proxies for academic ability, such as test scores or grade point averages. It is nevertheless possible to use course-level data on ATAR cut-off scores, which establish a lower bound for the course to which the graduate was admitted, and the statistical property of the cut-off ATAR scores, which are ranks uniformly distributed in the 0-100 range. Consider the regression model:

$$
y_{i}=\beta_{0}+\sum_{j=2}^{m} \alpha_{j} D_{i j}+\gamma A_{i}+\varepsilon_{i}
$$

where $D_{i j}$ is a set of dummy variables indicating course and $A_{i}$ is the ATAR of student $i$, which is unobservable. Two types of selection are likely to occur. First, universities select students on the basis of their ATAR. Second, students self-select into their preferred university, presumably also based on ATAR as those with high scores may be less willing to enrol in courses with low cut-offs. Both of these selection mechanisms will result in dependence between $A_{i}$ and $D_{i j}$. Both variables do not

\footnotetext{
${ }^{5}$ The resulting university quality scores are strongly correlated with those produced by Williams (2007) $(r=$ 0.807), which were relatively more focused on institutional research performance.

${ }^{6}$ The ATAR is not used in Queensland, which retains its Overall Position (OP) system. A table is produced by tertiary education authorities to allow conversion between OP and ATAR.
} 
violate the standard assumption that the error term $\varepsilon_{i}$ in model (1) has an expected value of zero conditional on $A_{i}$ and $D_{i j}$. If individual-level ATAR data were available, the estimation of Equation (1) would be unproblematic. However $A_{i}$ is not directly observed and estimating Equation (1) without it results in the compound error term $\gamma A_{i}+\varepsilon_{i}$ to be correlated with the course dummies $D_{i j}$, leading to inconsistent OLS estimates.

This problem is solved as the course in which the graduate enrolled and the corresponding ATAR cutoff score, which will be denoted by $c_{i}$, are observed. The key feature of the ATAR is that it is a rank and consequently it uniformly distributes between the values of 0 and 100 . Since, by construction, the ATAR of each enrolled student is at least as high as the minimum course ATAR cut-off score it is possible to exploit the statistical properties of the uniform distribution and the observed cut-off to control to non-random selection into each course area to obtain the regression model (see the Appendix for the formal derivation and Heaton, 2014):

$$
y_{i}=\beta_{0}+\sum_{j=2}^{m} \alpha_{j} D_{i j}+\gamma \frac{100+c_{i}}{2}+\eta_{i}
$$

where

$$
\eta_{i}=\gamma A_{i}-\gamma \frac{100+c_{i}}{2}+\varepsilon_{i}
$$

Since the expected value of the error term conditional on the course cut-off score is zero and its variance is $\sigma^{2}+\frac{\gamma^{2}}{12}\left(100-c_{i}\right)^{2}$, the parameters in Equation (2) may be consistently estimated by ordinary least squares (OLS) with robust estimation. Therefore, to the extent that the ATAR is a valid proxy, this approach allows one to control for graduates' academic ability and preparedness, estimating the true effect of attending a particular course at a specific university.

The empirical analysis is based on a two-stage estimation methodology to estimate the relationship between university quality and graduate starting salaries. This approach is not commonly used in the university quality literature (e.g. Card and Krueger, 1992) but it offers two important advantages. First, it avoids aggregation bias in the standard errors resulting from the inclusion of university-level variables in the wage regressions (Moulton, 1986). Second, it allows one to illustrate the diversity in returns to attending specific universities and determine the extent to which these are associated with institutional quality. 
As a result in the first stage, the normalised starting salary $y_{i}$ is regressed on course area $D_{i j}$, the ATAR cut-off score $c_{i}$, a set of controls consisting of gender, occupation, industry and survey year dummies $X_{i}$, and a separate dummy variable for each university $U_{i k}$. Formally:

$$
y_{i}=\beta_{0}+\sum_{j=2}^{29} \alpha_{j} D_{i j}+\gamma \frac{100+c_{i}}{2}+\delta X_{i}+\sum_{k=2}^{35} \theta_{k} U_{i k}+\eta_{i}
$$

Given the likely heteroskedasticity, Equation (4) is estimated using OLS with White’s standard errors (first stage). The estimates of the average university premia $\widehat{\theta_{k}}$ are then regressed on the university quality indicator $Q_{k}$ (second stage):

$$
\widehat{\theta_{k}}=\beta_{0}+\alpha Q_{k}+\varepsilon_{k} .
$$

Equation (5) is estimated using OLS. As Heaton (2014) shows that the second-stage OLS estimator is consistent due to the fact that the error introduced by using $\hat{\theta}$ instead of $\theta$ is smaller than the standard regression error.

\section{Results}

We begin by estimating a variant of Equation (4) with a full set of university dummies and controls for survey year only, and present the estimated university effects in Figure 1. Each estimate is depicted with its 95\% confidence interval. These results show a wide range in salary premia, with 22 p.p. separating the universities with the highest and lowest average starting salaries relative to the regional mean. For the most part, the increase in estimated premia is fairly gradual and even, with the exception of the two institutions at the top end of the distribution (go86 and go82) and the one at the bottom (run1). The universities go86 and go82 were the only two with a larger premium than the omitted reference university (go87), based on the fact that their estimated premia were greater than zero. In the case of go87, this does not appear to be statistically significant. A series of F-tests indicates that the university dummies are jointly different from each other, as were the dummies constituting each of the five institutional groups. The latter result underscores the benefit of investigating individual universities previously highlighted by Birch et al. (2009), and could explain why in their study there was little variation in starting salaries across university groups.

GO8 and ATN universities are generally over-represented in the top of the distribution whilst the lowest-ranked GO8 (go85) is 20th out of 35 universities, with the lowest-ranked ATN (atn1) 21st 
overall. There is no clear pattern observed in relation to the other university groups. Notably, university (and survey year) account for very little of the variation in starting salaries, with an $R$ squared of 0.024. Birch et al. (2009) report a similar figure (0.015).

[Figure 1 around here]

Next, to control for differences in exogenous enrolment and personal characteristics, we augment the initial model with a set of dummies for course area, a dummy variable for females and the ATAR cut-off score for the course in which the graduate was enrolled.

The estimated university effects are presented in Figure 2 and the estimates on the control variables are given in the Model 2 column in Table 3. This model explains much more of the variation in starting salaries, with an $R$-squared of 0.154 . Of the additional controls, the 29 course area dummies provide the greatest increase in explanatory power, accounting for $14.1 \%$ of the variance in starting salaries.

Looking at the university effects in Figure 2, the addition of controls for enrolment and personal characteristics narrows the range in university premia, with only 12 p.p. separating the institutions at the top and bottom of the distribution. This increase in estimated premia is even more gradual with the addition of controls for enrolment and personal characteristics, which, given the importance of course area as a determinant of starting salaries, suggests that the outliers seen in Figure 1 can be attributed largely to differences in the courses undertaken by students.

The university estimates from Models 1 and 2 are strongly correlated, implying that the addition of controls for enrolment and personal characteristics has not changed the relative order of the universities to a great extent. Four GO8 universities, including the reference university, are at the top. The overlapping error bars suggest few significant differences at the top and bottom of the distribution relative to the middle. An F-test soundly rejects the hypothesis that all 35 university dummies are equivalent.

[Figure 2 around here]

As shown in Table 3, starting salaries vary considerably on the basis of course area, in line with the findings of numerous earlier studies (e.g. Rumberger \& Thomas, 1993; Betts et al., 2007; Chia \& Miller, 2008; Birch et al., 2009). Sixty-one p.p. separate the highest-earning course area 
(dentistry) and the lowest (pharmacy); considerably more than the 12 p.p. separating the universities with the highest and lowest estimated premia.

[Table 3 around here]

The results reveal that the coefficient on the ATAR cut-off variable is small in magnitude at $0.03(0.03)$ and not statistically significant $(p>0.100)$. While seemingly counterintuitive, there are two plausible, non-mutually exclusive explanations for this result. First, high-ability individuals may self-select into course areas leading to better paid jobs, resulting in academic ability being captured by the course area dummies instead of the ATAR cut-off variable. To test this, we estimated Model 2 without the course area dummies. This resulted in the coefficient on the ATAR cut-off variable increasing to $0.15(0.03)$ and becoming statistically significant $(p<0.001)$, consistently with our prior.

Second, it could be that many students who gained admission with a low ATAR drop out prior to graduation and thus do not appear in the data. Evidence in support of this is given by Kemp and Norton (2014), who report higher attrition rates amongst low-ATAR applicants.

Finally for the first stage, we augment Model 2 with sets of dummies for occupation and industry. The estimated university effects are presented in Figure 3 and the results on the control variables are given in the Model 3 column of Table 3. Adding controls for occupation and industry further narrows the range between universities to 8 p.p., largely due to a reduction of the negative premia associated with universities at the bottom of the distribution. This implies that some of the university effect may be attributed to graduates from certain universities being less likely to secure high-paying roles. Again, the F-tests establish that the estimated premia are still jointly different from each other, both in aggregate and within institutional groups.

[Figure 3 around here]

The inclusion of controls for occupation and industry increases the explanatory power of the model considerably, with an $R$-squared of 0.259 . The coefficients on both the occupation and industry dummies vary notably, indicating that employment characteristics play a key role in starting salary determination. Course area remain an important determinant of starting salaries, with much variation still observed after controlling for occupation and industry, albeit with changes in the premia 
associated with particular courses. No substantive changes are observed in relation to the coefficients on the ATAR cut-off and female variables.

Having established that starting salary premia vary significantly across universities, we attempt to explain them on the basis of the composite quality indicator. Since employment characteristics are likely endogenous, the second-stage model is based on the university estimates from Model 2. Figure 4 plots the university estimates against the quality indicator measured in $z$ scores. Again, the error bars represent the 95\% confidence interval around each university estimate. The figure also depicts the OLS regression line formalised in Equation (5) to relate the two variables. The coefficient on $Q_{k}$ is 0.1934 (0.062), indicating a positive and significant relationship between university premia and quality, implying that an increase of one standard deviation in quality is associated with an increase in estimated premium of 0.19 p.p.. This magnitude is small relative to that relating premia with the corresponding course area.

[Figure 4 around here]

Only four universities deviate from the predicted relationship, exhibiting low university quality scores and relatively high premia compared with universities at a similar level of quality (run2, run5, uni1, uni5). This could be the result of institutional attributes not measured (or proxied) by the quality indicator that could lead to superior graduate labour market outcomes, such as links with industry or a favourable reputation with employers. Alternatively, it could be the result of local labour market factors not eliminated through the normalisation procedure. Estimating Equation (5) without these outlier institutions improves the fit considerably, with an $R$-squared of 0.532 . The magnitude of the estimated coefficient on $Q_{k}$ also increases to 0.2681 (0.047), providing further evidence of a general association between university quality and starting salaries.

To check the validity of the results, we perform two robustness checks. First, because graduates in full-time employment may constitute a non-random subsample, we add graduates not in full-time work and estimate Model 2 using Heckman's (1979) two-step procedure. The results obtained suggest no significant selection effect, and the university estimates are little affected by the inclusion of the selection bias control factor. 
Second, we estimate Model 2 with the logarithm of the starting salary as the dependent variable to determine the extent to which regional effects influence the university premia. In terms of the first stage, using the logarithm instead of the starting salary normalised by region results in substantial changes to the university estimates, with evidence of clustering by region. Moreover, the model estimated using the logarithm has a somewhat lower fit, with an $R$-squared of 0.115 .

In terms of the second stage, regressing the estimated premia on university quality still yields a positive and significant relationship, but the strength of the relationship is weaker, with an $R$ squared of 0.179 . From these results, we prefer the normalisation approach to transform the dependent variable, though in either case the results support the existence of a positive and significant, albeit small, relationship between quality and university premia.

\section{Conclusions and implications}

The empirical results are broadly consistent with much of the existing literature that finds a positive but weak association between university quality and graduate earnings (e.g. Brewer et al., 1999; Chevalier \& Conlon, 2003; McGuinness, 2003; Black \& Smith, 2004; Holmlund, 2009). Perhaps the most relevant finding is that the range of estimated university effects is quite narrow-12 p.p. after controlling for exogenous personal and exogenous characteristics—and that there are few significant differences in estimated effects at the top and bottom of the universities' distribution relative to the middle.

Given the degree of heterogeneity in university characteristics, these results are somewhat unexpected. We highlight three plausible explanations. First, the quality of undergraduate teaching may be more homogenous across universities than is implied by these characteristics, with the result that human capital production in Australian higher education institutions is only weakly related to the university attended. Since the sector is characterised by large public institutions subject to considerable central governmental regulation and oversight, there is less scope for large crossuniversity variation.

Second, it could be that university characteristics such as faculty qualifications and staff to student ratios are not as important to the production of human capital as this and other studies have assumed (e.g. Rumberger \& Thomas, 1993; Holmlund, 1999; Betts et al., 2007). 
Third, it could be that employers do not use institutional quality as a signal of unobserved productivity, at least for young bachelor degree graduates. Employers, facing imperfect information about the productivity of recent graduates may be unwilling to pay a premium solely on the basis of attending a particular university. Any human capital benefits associated with attending a prestigious university would therefore only be reflected in graduates' salaries once employers had learned their actual ability, potentially several years after labour market entry. To investigate this last point further, we estimate a simple panel data model with a random individual effect based on the Beyond Graduation Survey (BGS), which follows up a subset of graduates three years after completing the 2009 GDS. Due to the relatively small number of graduates in the BGS analysis sample $(n=1015)$, we regress the logarithm of salary on the university quality indicator, time, an interaction term of these two variables, and the personal and enrolment variables from Model 2. The estimated coefficient on the quality*time interaction term is $0.0102(0.010)$ and is not statistically significant ( $p$ $>0.100$ ), providing some evidence that graduates from high-quality universities do not experience stronger early-career salary growth than those from lower-quality institutions after controlling for personal and enrolment characteristics. This is consistent with the proposition that human capital production is relatively homogenous across institutions.

From a policy perspective, the results suggest that even under a deregulated fee system Australian universities appear to have little justification for charging undergraduate fees according to 'quality' differences. Few, if any, significant differences in the returns to education between institutions at the top and middle of the distribution remain after controlling for differences in course offerings and student characteristics. This implies that the Australian higher education sector is not characterised by a handful of elite universities, at least as far as the graduate labour market is concerned. Universities would be more justified in setting their fees, at least in part, on the expected labour market outcomes for different course areas. Under the current system, students in economics and dentistry courses, for example, pay the same contribution, in spite of the latter group having a far greater earnings potential than the former. 


\section{References}

Becker, G.S. (1964). Human capital: A theoretical and empirical analysis with special reference to education. New York: National Bureau of Economic Research.

Betts, J., Ferrall, C., \& Finnie, R. (2007). The role of university characteristics in determining postgraduation outcomes: Panel evidence from three recent Canadian cohorts. Statistics Canada, Research Paper No. 292.

Birch, E.R., Li, I., \& Miller, P.W. (2009). The influences of institution attended and field of study on graduates’ starting salaries. Australian Economic Review, 42 (1), 42-63.

Black, D.A., \& Smith, J.A. (2004). How robust is the evidence on the effects of college quality? Evidence from matching. Journal of Econometrics, 121 (1-2), 99-124.

Black, D.A., \& Smith, J.A. (2006). Estimating the returns to college quality with multiple proxies for quality. Journal of Labor Economics, 24 (3), 701-728.

Brand, J.E., \& Halaby, C.N. (2003). Regression and matching estimates of the effects of elite college attendance on career outcomes. University of Wisconsin-Madison, Discussion Paper.

Brewer, D.J., Eide, E.R., \& Ehrenberg, R.G. (1999). Does it pay to attend an elite private college? Cross-cohort evidence on the effects of college type on earnings. Journal of Human Resources, 34 (1), 104-123.

Card, D., \& Krueger, A.B. (1992). Does school quality matter? Returns to education and the characteristics of public schools in the United States. Journal of Political Economy, 100 (1), $1-40$.

Chevalier, A., \& Conlon, G. (2003). Does it pay to attend a prestigious university? Centre for the Economics of Education, London School of Economics and Political Science, Discussion Paper No. 33.

Chia, G., \& Miller, P.W. (2008). Tertiary performance, field of study and graduate starting salaries. Australian Economic Review, 41 (1), 15-31.

Dale, S.B., \& Krueger, A.B. (2002). Estimating the payoff to attending a more selective college: An application of selection on observables and unobservables. Quarterly Journal of Economics, $117(4), 1491-1527$. 
Department of Industry, Innovation, Climate Change, Science, Research and Tertiary Education. (2013a). Students 2012: Selected higher education statistics. Canberra: Author.

Department of Industry, Innovation, Climate Change, Science, Research and Tertiary Education. (2013b). Staff 2012: Selected higher education statistics. Canberra: Author.

Graduate Careers Australia. (2010). Graduate salaries 2009. Melbourne: Author.

Graduate Careers Australia. (2013). Graduate destinations 2012. Melbourne: Author.

Guthrie, B., \& Johnson, T. (1997). Study of non-response to the 1996 Graduate Destination Survey. Canberra: Department of Employment, Education, Training and Youth Affairs.

Hanushek, E.A., Rivkin, S.G., \& Taylor, L.L. (1996). Aggregation and the estimated effects of school resources. Review of Economics and Statistics, 78 (4), 611-627.

Heaton, C. (2013). Estimating the effects of selective programs. Department of Economics, Macquarie University, Mimeo.

Heaton, C. (2014). Using estimated regression parameters as dependent variables. Department of Economics, Macquarie University, Mimeo.

Heckman, J.J. (1979). Sample selection bias as a specification error. Econometrica, 47 (1), 153-161.

Heckman, J.J., \& Robb, R. (1985). Alternative methods for evaluating the impact of interventions: An overview. Journal of Econometrics, 30 (1-2), 239-267.

Holmlund, L. (2009). The effect of college quality on earnings: Evidence from Sweden. Umeå University, Umeå Economic Studies No. 781.

Kemp, D., \& Norton, A. (2014). Review of the demand driven funding system. Canberra: Department of Education.

Kingston, P.W., \& Smart, J.C. (1990). The economic pay-off of prestigious colleges. In P.W.

Kingston \& L.S. Lewis, The high-status track: Studies of elite schools and stratification (pp. 147-174). Albany: State University of New York Press.

Lee, L.F. (1983). Generalized econometric models with selectivity. Econometrica, 51 (2), 507-512.

Long, M.C. (2008). College quality and early adult outcomes. Economics of Education Review, 27 (5), 588-602. 
McGuinness, S. (2003). University quality and labor market outcomes. Northern Ireland Economic Research Centre Working Paper Series no.78.

Milla, J. (2012). University quality and labor market outcomes of Canadian youth. Department of Economics and Finance, University of Guelph, Discussion Paper No. 2012-12.

Miller, P.W., \& Volker, P. (1983). Starting salaries and destinations of graduates in Australia. Bureau of Labour Market Research, Conference Paper No. 14.

Mishra, A., \& Ray, R. (2013). Spatial variation in prices and expenditure inequalities in Australia. Department of Economics, Monash University, Discussion Paper No. 34/13.

Monks, J. (2000). The returns to individual and college characteristics: Evidence from the National Longitudinal Survey of Youth. Economics of Education Review, 19 (3), 279-289.

Moulton, B.R. (1986). Random group effects and the precision of regression estimates. Journal of Econometrics, 32 (3), 385-397.

Rumberger, R.W., \& Thomas, S.L. (1993). The economic returns to college major, quality and performance: A multilevel analysis of recent graduates. Economics of Education Review, 12 (1), 1-19.

Spence, M. (1973). Job market signaling. Quarterly Journal of Economics, 87 (3), 355-374.

Thomas, S.L., \& Zhang, L. (2005). Post-baccalaureate wage growth within 4 years of graduation: The effects of college quality and college major. Research in Higher Education, 46 (4), 437-459.

Williams, R. (2007). Ranking Australian universities: Controlling for scope. Melbourne: The University of Melbourne, Melbourne Institute of Applied Economic and Social Research. 


\section{Appendix}

Formal derivation of control variable for non-random selection into course area and university:

Assume that:

$$
\begin{aligned}
& E\left(\varepsilon_{i} \mid c_{i},\left\{D_{i j}: j=1, \ldots, m\right\}\right)=0 \\
& \operatorname{Var}\left(\varepsilon_{i} \mid c_{i},\left\{D_{i j}: j=1, \ldots, m\right\}\right)=\sigma^{2} \\
& E\left(A_{i} \varepsilon_{i} \mid c_{i},\left\{D_{i j}: j=1, \ldots, m\right\}\right)=0 .
\end{aligned}
$$

Since, by construction, (i.e. $A_{i} \geq c_{i}$ ), it follows that $\forall n \in \mathbb{N}$ :

$$
E\left(A_{i}^{n} \mid c_{i},\left\{D_{i j}: j=1, \ldots, m\right\}\right)=E\left(A_{i}^{n} \mid\left\{D_{i j}: j=1, \ldots, m\right\}, A_{i} \geq c_{i}\right) .
$$

It can be shown that the truncated uniform density for the ATAR is

$$
f\left(A_{i} \mid A_{i}>c_{i}\right)=\frac{1}{100-c_{i}} 1\left(c_{i} \leq A_{i} \leq 100\right) .
$$

From standard results for uniform densities and Equation (5):

$$
\begin{aligned}
& E\left(A_{i} \mid c_{i},\left\{D_{i j}: j=1, \ldots, m\right\}\right)=\frac{1}{2}\left(100+c_{i}\right) \\
& \operatorname{Var}\left(A_{i} \mid c_{i},\left\{D_{i j}: j=1, \ldots, m\right\}\right)=\frac{1}{12}\left(100-c_{i}\right)^{2} .
\end{aligned}
$$

As an alternative to Equation(1), the following equivalent regression model can be estimated:

$$
y_{i}=\beta_{0}+\sum_{j=2}^{m} \alpha_{j} D_{i j}+\gamma \frac{100+c_{i}}{2}+\eta_{i}
$$

where

$$
\eta_{i}=\gamma A_{i}-\gamma \frac{100+c_{i}}{2}+\varepsilon_{i}
$$

Using Equations (7), (8) and (10), it is simple to show that $E\left(\eta_{i} \mid c_{i},\left\{D_{i j}: j=1, \ldots, m\right\}\right)=0$ and $\operatorname{Var}\left(\eta_{i} \mid c_{i},\left\{D_{i j}: j=1, \ldots, m\right\}\right)=\sigma^{2}+\frac{\gamma^{2}}{12}\left(100-c_{i}\right)^{2}$. Consequently, the parameters in Equation (9) may be consistently estimated by ordinary least squares (OLS), and the standard errors of the parameter estimates may be consistently estimated using White's heteroskedasticity-consistent covariance matrix estimator (robust estimation). 
Table 1

Summary statistics of explanatory variables. ${ }^{\mathrm{a}}$

\begin{tabular}{|c|c|c|c|}
\hline Variable & Mean & Variable & Mean (St. Dev.) \\
\hline Course area & & ATAR cut-off score & $57.808(15.347)$ \\
\hline Accounting & 0.066 & & \\
\hline Agriculture & 0.005 & Female & 0.627 \\
\hline Architecture & 0.007 & & \\
\hline Built environment & 0.024 & Occupation & \\
\hline Communications & 0.050 & Managers & 0.057 \\
\hline Computing and information tech. & 0.036 & Technicians and trades workers & 0.033 \\
\hline Environmental studies & 0.006 & Community and personal service workers & 0.042 \\
\hline Dentistry & 0.002 & Clerical and administrative workers & 0.126 \\
\hline Economics & 0.010 & Sales workers & 0.043 \\
\hline Education and training & 0.097 & Machinery operators and drivers & 0.002 \\
\hline Engineering and technology & 0.089 & Labourers & 0.008 \\
\hline Rehabilitation & 0.047 & (Professionals) & \\
\hline Health services and support & 0.037 & & \\
\hline Tourism and hospitality & 0.010 & Industry & \\
\hline Humanities and social sciences & 0.038 & Agriculture, forestry and fishing & 0.004 \\
\hline Languages & 0.009 & Mining & 0.017 \\
\hline Law & 0.028 & Manufacturing & 0.031 \\
\hline Para-legal studies & 0.010 & Electricity, gas and water supply & 0.010 \\
\hline Pharmacy & 0.023 & Construction & 0.034 \\
\hline Sport and leisure & 0.010 & Wholesale trade & 0.009 \\
\hline Mathematics & 0.003 & Retail trade & 0.065 \\
\hline Medicine & 0.014 & Accommodation and food services & 0.023 \\
\hline Nursing & 0.083 & Transport, postal and warehousing & 0.013 \\
\hline Psychology & 0.022 & Information media and telecommunications & 0.037 \\
\hline Sciences & 0.041 & Financial and insurance services & 0.057 \\
\hline Social work & 0.009 & Rental, hiring and real estate services & 0.013 \\
\hline Surveying & 0.002 & Administrative and support services & 0.024 \\
\hline Veterinary science & 0.003 & Public administration and safety & 0.070 \\
\hline Creative arts & 0.024 & Education and training & 0.123 \\
\hline \multirow[t]{2}{*}{ (Business and management) } & & Health care and social assistance & 0.222 \\
\hline & & Arts and recreation services & 0.017 \\
\hline Survey year & & Other services & 0.012 \\
\hline Year 2010 & 0.313 & (Professional, scientific and technical services) & \\
\hline Year 2011 & 0.342 & & \\
\hline (Year 2012) & & $n$ & 36,204 \\
\hline
\end{tabular}

a With the exception of ATAR cut-off score, all variables are dummy coded with $1=$ named value and $0=$ other values. Omitted reference categories are given in parentheses. 
Table 2

Summary statistics on the universities in our analysis sample.

\begin{tabular}{|c|c|c|c|}
\hline University $^{\mathrm{a}}$ & $n$ & $\begin{array}{r}\text { FTE staff per } 100 \\
\text { FTE students } \\
\end{array}$ & $\begin{array}{r}\text { Academic staff } \\
\text { with } \mathrm{PhD}(\%)\end{array}$ \\
\hline \multicolumn{4}{|c|}{ Group of Eight } \\
\hline go81 & 403 & 11.599 & 80.129 \\
\hline go82 & 533 & 7.777 & 76.599 \\
\hline go83 & 1,811 & 6.795 & 68.096 \\
\hline go84 & 2,348 & 6.610 & 77.536 \\
\hline go85 & 1,019 & 7.899 & 84.579 \\
\hline go86 & 901 & 6.789 & 70.940 \\
\hline \multicolumn{4}{|l|}{ (go87) } \\
\hline \multicolumn{4}{|c|}{ Australian Technology Network } \\
\hline atn1 & 2,606 & 4.155 & 70.145 \\
\hline atn2 & 2,665 & 4.097 & 69.708 \\
\hline atn3 & 1,982 & 3.674 & 71.137 \\
\hline atn4 & 1,756 & 4.057 & 57.132 \\
\hline atn5 & 1,750 & 2.980 & 62.664 \\
\hline \multicolumn{4}{|c|}{ Innovative Research Universities Australia } \\
\hline irua1 & 1,328 & 4.022 & 69.673 \\
\hline irua2 & 68 & 6.623 & 33.191 \\
\hline irua3 & 1,235 & 4.887 & 57.331 \\
\hline irua4 & 1,251 & 4.264 & 71.768 \\
\hline irua5 & 689 & 5.102 & 59.223 \\
\hline irua6 & 422 & 4.210 & 57.547 \\
\hline irua7 & 500 & 5.958 & 67.188 \\
\hline \multicolumn{4}{|c|}{ Regional Universities Network } \\
\hline run1 & 398 & 3.155 & 63.253 \\
\hline run2 & 243 & 2.700 & 56.596 \\
\hline run3 & 321 & 3.590 & 62.500 \\
\hline run4 & 410 & 3.347 & 59.050 \\
\hline run5 & 369 & 2.874 & 48.232 \\
\hline run6 & 259 & 4.961 & 68.468 \\
\hline \multicolumn{4}{|c|}{ Ungrouped universities } \\
\hline uni1 & 686 & 3.640 & 45.199 \\
\hline uni2 & 1,333 & 4.453 & 74.573 \\
\hline uni3 & 598 & 3.530 & 64.610 \\
\hline uni4 & 1,123 & 3.024 & 59.603 \\
\hline uni5 & 777 & 3.716 & 50.739 \\
\hline uni6 & 1,100 & 3.634 & 66.736 \\
\hline uni7 & 1,461 & 3.900 & 65.124 \\
\hline uni8 & 860 & 3.452 & 56.688 \\
\hline uni9 & 338 & 6.323 & 63.549 \\
\hline uni10 & 503 & 3.128 & 56.732 \\
\hline uni11 & 517 & 4.086 & 59.103 \\
\hline
\end{tabular}

a All variables are dummy coded with $1=$ named value and $0=$ other values. The omitted reference university is go87.

b FTE = full-time equivalent. 
Table 3

Results on control variables. ${ }^{\mathrm{a}, \mathrm{b}}$

\begin{tabular}{|c|c|c|}
\hline Variable & Model 2 & Model 3 \\
\hline \multicolumn{3}{|l|}{ 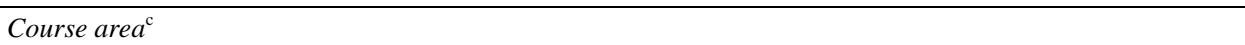 } \\
\hline Accounting & $0.62(0.57)$ & $-1.75(0.57)^{* * *}$ \\
\hline Agriculture & $-8.21(1.98)^{* * *}$ & $-3.06(1.97)$ \\
\hline Architecture & $-19.02(1.60)^{* * *}$ & $-17.52(1.58)^{* * *}$ \\
\hline Built environment & $7.99(1.02)^{* * *}$ & $4.23(0.99) * * *$ \\
\hline Communications & $-12.08(0.65)^{* * *}$ & $-8.98(0.65)^{* * *}$ \\
\hline Computing and information technology & $6.48(0.77)^{* * *}$ & $4.15(0.73)^{* * *}$ \\
\hline Environmental studies & $0.63(1.99)$ & $-1.86(1.70)$ \\
\hline Dentistry & $39.41(4.56)^{* * *}$ & $38.51(4.47)^{* * *}$ \\
\hline Economics & $5.28(1.34)^{* * *}$ & $3.50(1.27)^{* * *}$ \\
\hline Education and training & $8.25(0.55)^{* * *}$ & $1.37(0.83)^{*}$ \\
\hline Engineering and technology & $21.04(0.60)^{* * *}$ & $13.91(0.59)^{* * *}$ \\
\hline Rehabilitation & $11.36(0.71)^{* * *}$ & $7.08(0.88)^{* * *}$ \\
\hline Health services and support & $5.11(0.86)^{* * *}$ & $3.44(0.95)^{* * *}$ \\
\hline Tourism and hospitality & $-9.62(1.26)^{* * *}$ & $0.44(1.27)$ \\
\hline Humanities and social sciences & $-4.06(0.76)^{* * *}$ & $-2.36(0.70)^{* * *}$ \\
\hline Languages & $-5.42(1.57)^{* * *}$ & $-4.14(1.39)^{* * *}$ \\
\hline Law & $6.67(0.95)^{* * *}$ & $6.73(0.93)^{* * *}$ \\
\hline Para-legal studies & $-5.92(1.42)^{* * *}$ & $-3.52(1.32)^{* * *}$ \\
\hline Pharmacy & $-21.60(0.97)^{* * *}$ & $-14.22(1.04)^{* * *}$ \\
\hline Sport and leisure & $-6.01(1.49)^{* * *}$ & $-3.63(1.41)^{* *}$ \\
\hline Mathematics & $6.74(2.34)^{* * *}$ & $3.06(2.11)$ \\
\hline Medicine & $19.77(1.36)^{* * *}$ & $16.56(1.45)^{* * *}$ \\
\hline Nursing & $-0.54(0.59)$ & $-5.00(0.82)^{* * *}$ \\
\hline Psychology & $-2.92(1.00)^{* * *}$ & $-1.41(0.91)$ \\
\hline Sciences & $-4.91(0.87)^{* * *}$ & $-4.58(0.79)^{* * *}$ \\
\hline Social work & $5.33(1.25)^{* * *}$ & $3.63(1.21)^{* * *}$ \\
\hline Surveying & $12.91(2.91)^{* * *}$ & $8.70(2.84)^{* * *}$ \\
\hline Veterinary science & $-3.44(1.86)^{*}$ & $-5.73(1.83)^{* * *}$ \\
\hline Creative arts & $-17.15(0.92)^{* * *}$ & $-12.22(0.88)^{* * *}$ \\
\hline ATAR cut-off score & $0.03(0.03)$ & $0.04(0.03)$ \\
\hline Female & $-3.89(0.32)^{* * *}$ & $-3.70(0.30)^{* * *}$ \\
\hline \multicolumn{3}{|l|}{ Occupation $^{\mathrm{d}}$} \\
\hline Managers & & $0.23(0.62)$ \\
\hline Technicians and trades workers & & $-9.68(0.79)^{* * *}$ \\
\hline Community and personal service workers & & $-10.24(0.82)^{* * *}$ \\
\hline Clerical and administrative workers & & $-9.53(0.43)^{* * *}$ \\
\hline Sales workers & & $-16.26(0.73)^{* * *}$ \\
\hline Machinery operators and drivers & & $-15.21(3.08)^{* * *}$ \\
\hline Labourers & & $-24.08(1.94)^{* * *}$ \\
\hline \multicolumn{3}{|l|}{ Industry ${ }^{\mathrm{e}}$} \\
\hline Agriculture, forestry and fishing & & $-0.84(2.11)$ \\
\hline Mining & & $34.39(1.26)^{* * *}$ \\
\hline Manufacturing & & $3.76(0.80)^{* * *}$ \\
\hline Electricity, gas and water supply & & $13.09(1.21)^{* * *}$ \\
\hline Construction & & $10.28(0.83)^{* * *}$ \\
\hline Wholesale trade & & $-3.35(1.37)^{* *}$ \\
\hline Retail trade & & $-12.00(0.71)^{* * *}$ \\
\hline Accommodation and food services & & $-14.35(0.94)^{* * *}$ \\
\hline Transport, postal and warehousing & & $1.50(1.26)$ \\
\hline Information media and telecommunications & & $-3.63(0.72)^{* * *}$ \\
\hline Financial and insurance services & & $9.21(0.61)^{* * *}$ \\
\hline Rental, hiring and real estate services & & $-1.45(1.22)$ \\
\hline Administrative and support services & & $-6.20(0.81)^{* * *}$ \\
\hline
\end{tabular}


Public administration and safety

Education and training

Health care and social assistance

Arts and recreation services

Other services

Controls

University

Survey year

$n$

Prob $>$ F

$R$-squared
$9.46(0.52)^{* * *}$

$5.03(0.78)^{* * *}$

$1.87(0.67)^{* * *}$

$-9.57(1.06)^{* * *}$

$-4.42(1.30)^{* * *}$

Heteroskedastic-consistent standard errors are in parentheses.

b The dependent variable is starting salary normalised by employment region.

c The omitted reference category is business and management.

d The omitted reference category is professionals.

e The omitted reference category is professional, scientific and technical services.

* $\quad$ Significant at $10 \%$.

** $\quad$ Significant at $5 \%$.

$* * * \quad$ Significant at $1 \%$. 
Figure 1. Estimated university effects from Model 1, with 95\% confidence intervals.

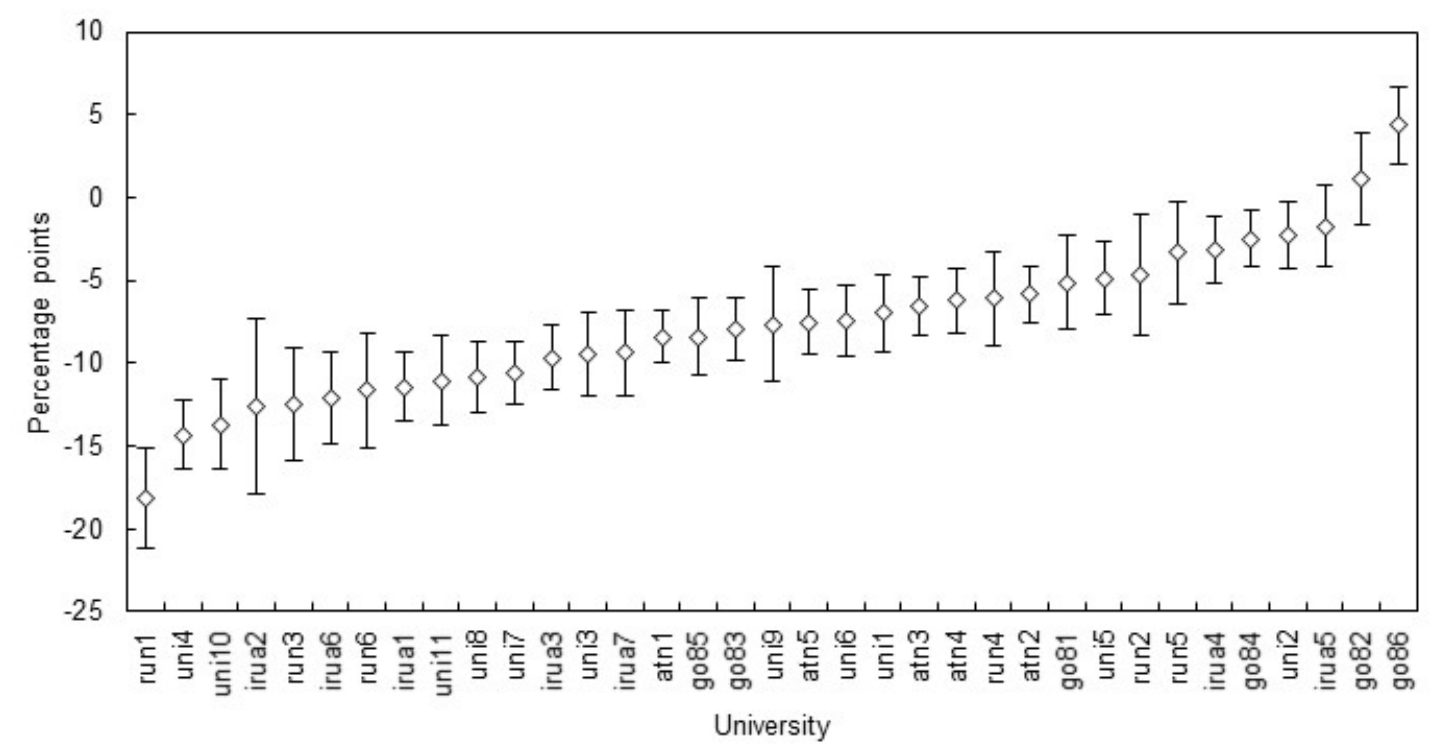

Figure 2. Estimated university effects from Model 2, with 95\% confidence intervals.

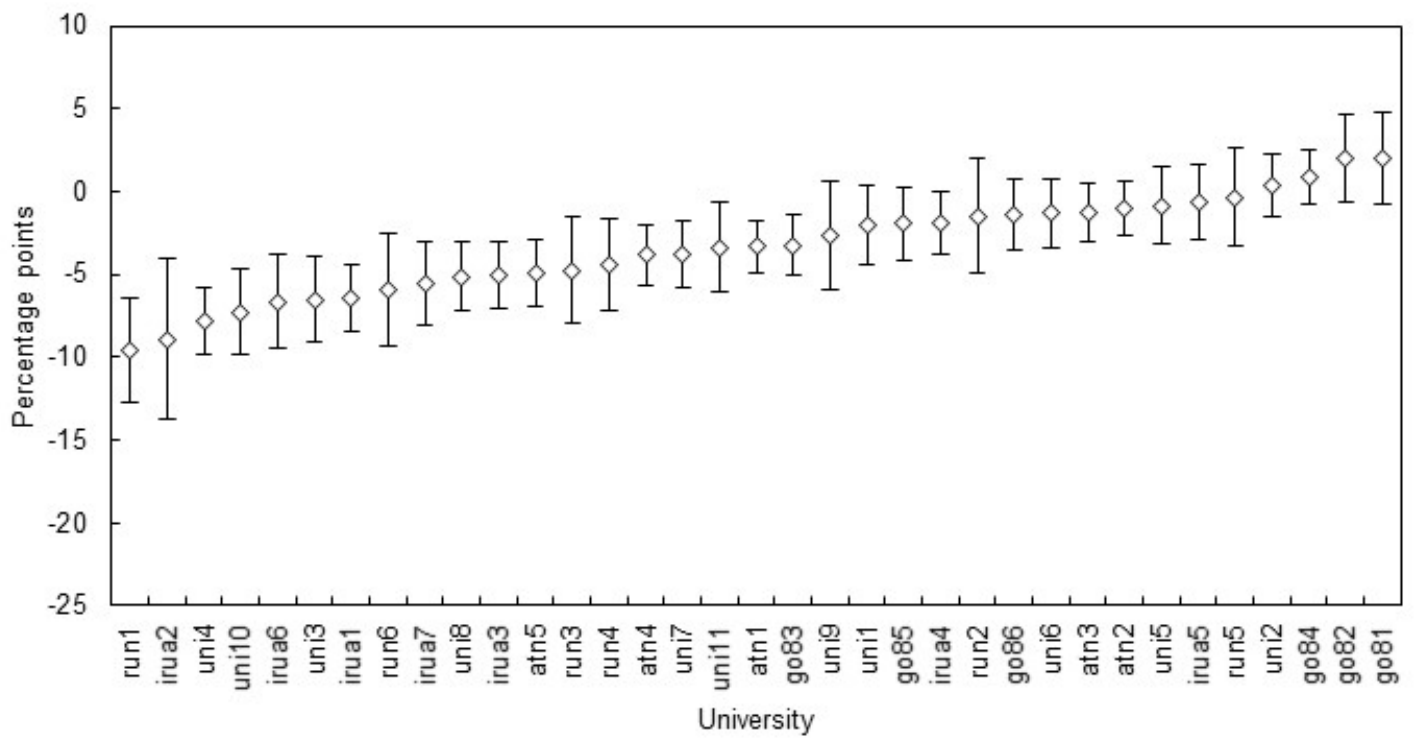


Figure 3. Estimated university effects from Model 3, with 95\% confidence intervals.

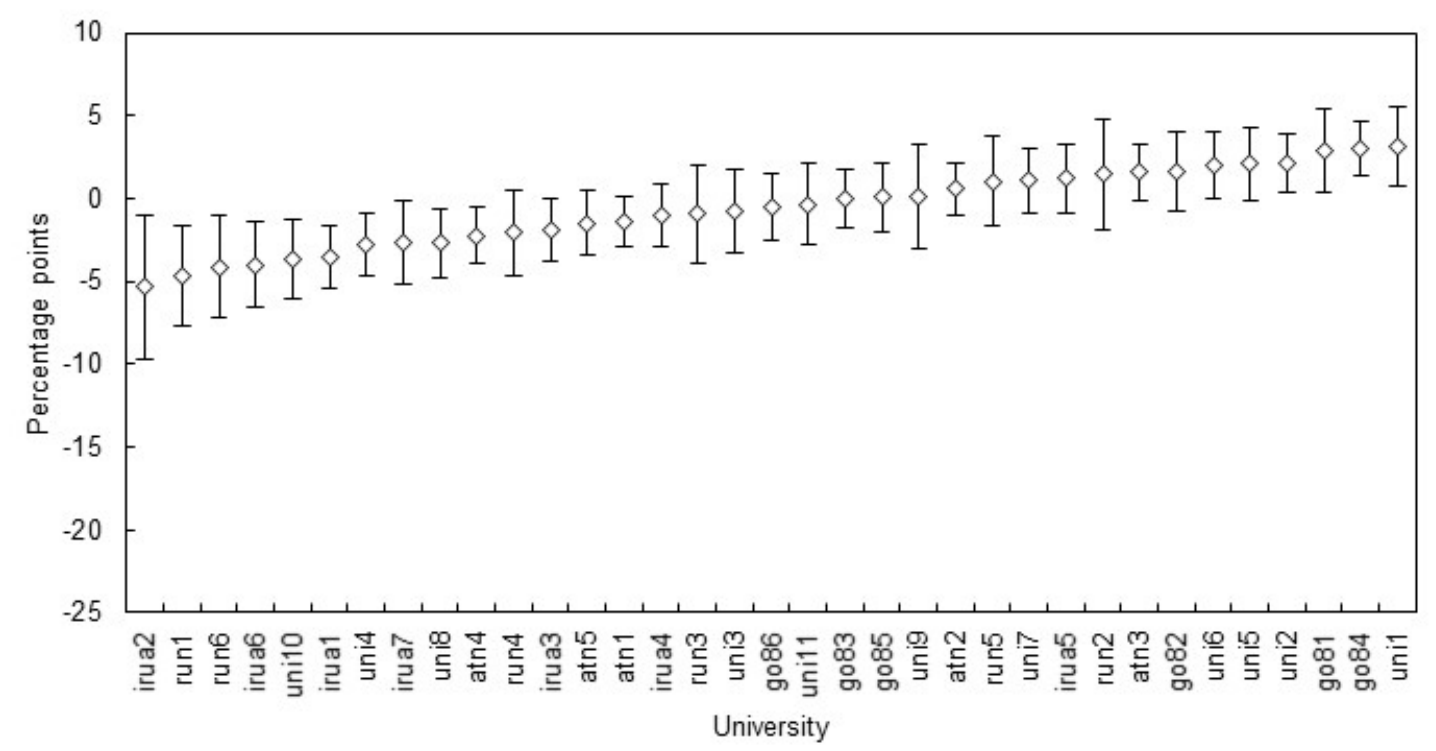

Figure 4. Estimated university effects from Model 2 vs. university quality scores.

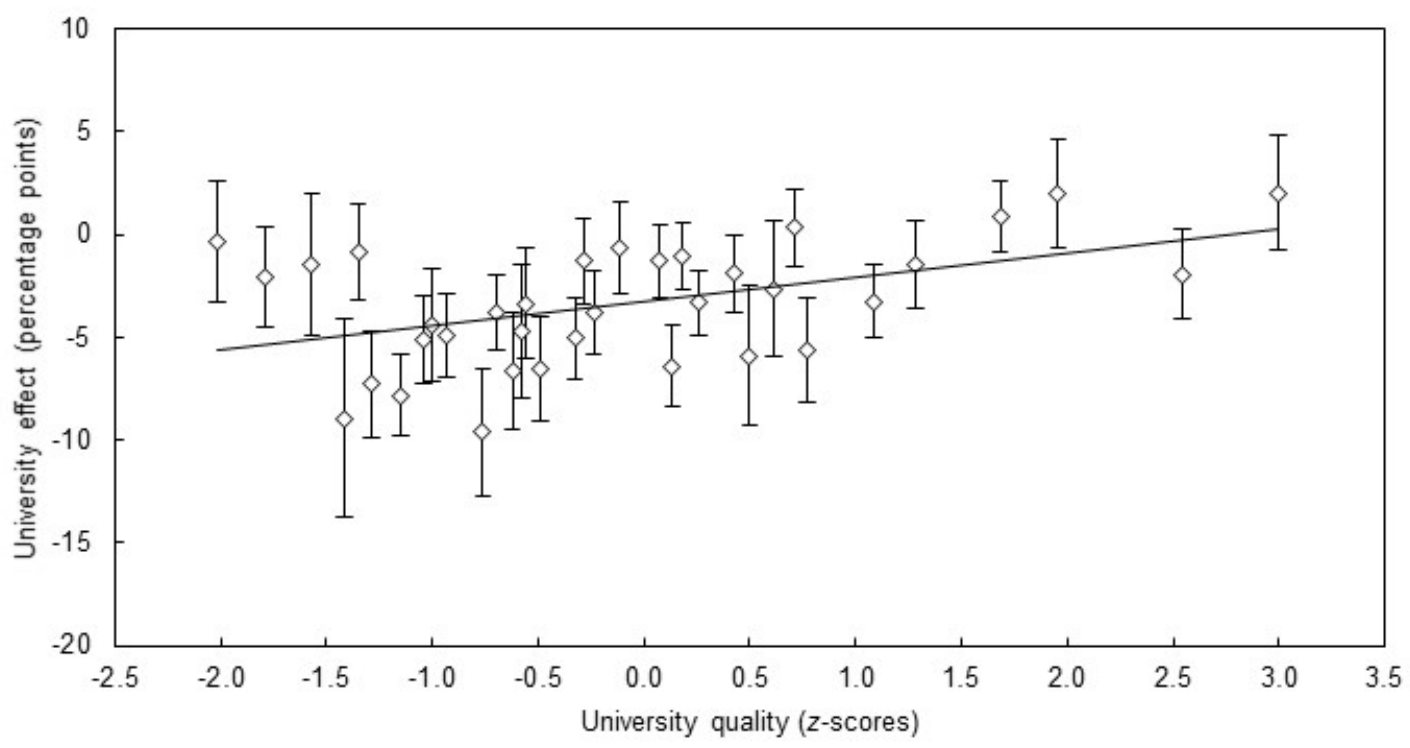

